\title{
Altered Peripheral Invariant Natural Killer T Cells in Atopic Dermatitis
}

Edit Gyimesi ${ }^{1}$, Georgina Nagy ${ }^{2,3}$, Éva Remenyik², Sándor Sipka', Margit Zeher ${ }^{1}$, Tamás Bíró $^{4}$, Andrea Szegedii ${ }^{2,3}$

${ }^{1} 3^{\text {rd }}$ Department of Internal Medicine and Departments of ${ }^{2}$ Dermatology, ${ }^{3}$ Dermatological Allergology and ${ }^{4}$ Physiology, University of Debrecen, Medical and Health Science Center, Research Center for Molecular Medicine, Debrecen, Hungary

Correspondence:

Edit Gyimesi PhD

Móricz Zs str. 22., Debrecen, 4032 Hungary

Tel./Fax: 36-52-255218

E-mail: egyimesi@freemail.hu

Running head: iNKT Cells in Atopic Dermatitis 


\begin{abstract}

\section{Background}

Conflicting data exist on the number of invariant NKT (iNKT) cells in atopic dermatitis (AD); furthermore, no data have been published on their functional capacity.
\end{abstract}

\title{
Methods
}

The frequency and number of circulating 6B11+CD3+ iNKT cells and their CD4+ and CD4subpopulations were evaluated in peripheral blood obtained from 41 patients with AD by fourcolor flow cytometry. Likewise, functional properties of iNKT cells were measured by five-color intracellular cytokine staining.

\section{Results}

The number and percentage of total iNKT cells and their CD4/CD8 subpopulations were significantly lower than the controls. Of further importance, the CD4-CD8- (double negative: DN) iNKT subgroup showed the strongest positive correlation with total iNKT cells. In addition, the DN subgroup exhibited the most pronounced functional alteration with significantly decreased levels of intracellular IFN $\gamma$ and significantly increased levels of intracellular IL-4 in AD patients compared with the controls.

\section{Conclusion}

The significantly altered number and cytokine production of iNKT cells from AD patients suggests that these cells may play an important role in the pathogenesis of AD.

\section{Key words}

Atopic dermatitis-invariant natural killer T cell-cytokine-flow cytometry 


\section{INTRODUCTION}

Atopic dermatitis (AD) is a chronic, pruritic inflammatory skin disease with a prevalence of $10-20 \%$ in children and $1-3 \%$ in adults, which significantly impairs quality of life of affected patients [1]. The interplay of several factors including susceptibility genes, environmental triggers and immunologic responses results in the development of the clinical phenotype of AD [2]. There are certain theories proposing that sequential helper $\mathrm{T}$ (Th) lymphocyte activation plays a role in the pathogenesis of AD. According to these theories, the predominance of Th2 lymphocytes in acute skin lesions of the initial phase is replaced by Th1 cell subsets during the persisting chronic phase of the disease [3]. Investigations of new $\mathrm{T}$ cell subsets in patients with $\mathrm{AD}$ revealed the involvement of naturally occurring $\mathrm{CD} 4+\mathrm{CD} 25+$ regulatory $\mathrm{T}$ cells; moreover, a possible role for Th17 and Th22 cells in AD was also suggested [4-6]. In addition to adaptive immune system alterations, recent data suggest important roles for both innate immune responses and skin barrier defects in the pathogenesis of $\mathrm{AD}[7,8]$.

In the last decade, despite their small number in the peripheral blood, a heterogeneous subpopulation of mature T cells, i.e., human invariant natural killer T (iNKT) cells, have entered into the focus of immunological investigations.

These cells express both the semi-invariant $\mathrm{T}$ cell receptor (TCR) and the NK cell receptor NKRP1A (CD161) [9-11]. The majority of human iNKT cells express TCRs consisting of the $\mathrm{V} \alpha 24 / \mathrm{J} \alpha 18 \alpha$ chain paired preferentially with the V $\beta 11 \beta$ chain [12]. They are divided into four subsets [CD4+, CD8+, double negative (DN), and double positive (DP)] and are activated by glycolipid antigens presented by CD1d on antigen presenting cells [13, 14].

iNKT cells play important effector and immune regulatory roles through their potent cytotoxicity and rapid secretion of cytokines [15]. They form a bridge between innate and 
adaptive immune responses, and of further importance, iNKT cells have been implicated in numerous human diseases $[16,17]$. Namely, a selective reduction in iNKT cell number has been shown in various autoimmune syndromes such as systemic sclerosis, systemic lupus erythematosus, and type I diabetes mellitus [18-22]. These cells have also been reported to play an active role in various skin diseases, such as allergic contact dermatitis, but the relationship between AD and iNKT cells has not been thoroughly investigated [23, 24].

The unique ability of iNKT cells to produce high amounts of both Th1-type (IFN $\gamma$ ) and Th2-type (IL-4) cytokines suggested the possibility that they may have a pathogenic role in AD [11]. Indeed, few and conflicting results have been published on iNKT cell frequencies and numbers in $\mathrm{AD}$ to date; however, the functional properties of iNKT cells have not been discovered $[25,26]$. Hence, the aim of our present study was to elucidate whether the frequency and/or the absolute number of peripheral iNKT cells and their different subsets are altered in AD patients; furthermore, their effector functions were investigated by examining intracellular IFN $\gamma$ and IL-4 cytokine production. 


\section{MATERIALS AND METHODS}

\section{Patients and Controls}

Forty-one patients with AD (16 female and 25 male, mean age $18.59 \pm 8.9$ years) and 16 healthy non-atopic controls (HCs) (11 female and 5 male, mean age $18.9 \pm 5.9$ years) were selected. AD patients fulfilled the diagnostic criteria established by Hanifin and Rajka [27]. All participants gave written informed consent according to the Declaration of Helsinki Principles. The severity of the disease was determined by the SCORAD (SCORe Atopic Dermatitis) index $[28,29]$. The mean objective SCORAD was $26.7 \pm 13.1$. When the subjective scores were also added, the mean SCORAD was $41.2 \pm 14.6$. The median serum total $\mathrm{IgE}$ was $584.3 \mathrm{kU} / \mathrm{L}$ with a range of 251.3-1245.0 kU/L, and the median serum lactate dehydrogenase (LDH) was $475 \mathrm{U} / \mathrm{L}$ with a range of 268.1-732.4 U/L, reference: 230-460 U/L. Patients had not received any oral glucocorticosteroids, or other systemic immunomodulatory agents, for at least 4 weeks and had not been treated with antihistamines or topical corticosteroids for at least 5 days before the collection of blood samples.

\section{Isolation of peripheral blood mononuclear cells (PBMC)}

Heparin anti-coagulated blood samples were layered over Histopaque-1077 (SigmaAldrich Chemie GmbH, Steinheim, Germany) and centrifuged at $700 x g$ for 30 minutes, and the mononuclear cells were isolated from the plasma-Ficoll interface.

\section{Determination of frequency and number of iNKT cells and CD4/CD8 iNKT cell subsets by flow cytometry}

The number and frequency of iNKT cells were determined by flow cytometry on PBMCs from 41 patients with $\mathrm{AD}$ using anti-CD3 and 6B11 (specific for the CDR3 loop on the Va24 
chain of the TCR) monoclonal antibodies (mAbs). Cells $\left(1 \times 10^{6}\right)$ were preincubated with 100 $\mu \mathrm{g} / \mathrm{mL}$ purified human $\mathrm{IgG}$ (Sigma) for 20 minutes on ice to prevent nonspecific binding to $\mathrm{Fc}$ receptors. After two washes in staining buffer (phosphate buffered saline, 5\% fetal calf serum, and $1 \%$ bovine serum albumin, all from Sigma), cells were then incubated with anti-CD3fluorescein isothiocyanate (FITC), 6B11-phycoerythrin (PE) (BD Pharmingen, San Jose, CA, USA), anti-CD4-PE-Texas Red (ECD) and anti-CD8-PE-Cyanine7 (PC7) (Immunotech, Marseille, France) mAbs for 45 minutes on ice. Cells were then washed and analyzed by four color flow cytometry on a Beckman Coulter FC500 flow cytometer and CXP software. For all staining experiments, appropriate isotype-matched controls were included. The absolute cell numbers were calculated by applying the two platform method using lymphocyte counts.

\section{Determination of functional properties of iNKT cells and their CD4/CD8 subgroups by intracellular cytokine analysis}

PBMCs of $10 \mathrm{AD}$ patients and $10 \mathrm{HCs}$ were investigated. Intracellular cytokine levels of iNKT cells and their CD4/CD8 subsets were determined by five-color flow cytometry as described [30]. Briefly, after stimulating PBMCs with $25 \mathrm{ng} / \mathrm{mL}$ phorbol-12-myristate 13-acetate (PMA) and $1 \mu \mathrm{g} / \mathrm{mL}$ ionomycin (Io) in the presence of $10 \mu \mathrm{g} / \mathrm{mL}$ Golgistop Brefeldin A (all from Sigma), the cells were washed, and surface staining of the cells was performed with appropriate mAbs to CD3 (FITC-labeled for IL-4-allophycocyanin (APC) staining and APClabeled for IFN $\gamma$-FITC staining, both from BD Pharmingen), 6B11, CD4 and CD8. The cells were then fixed and permeabilized with Intraprep $^{\mathrm{TM}}$ permeabilization reagent (Immunotech) according to the manufacturer's instructions, and intracellular cytokines were stained with IFN $\gamma$ FITC or IL-4-APC mAbs (both from BD Pharmingen) for 30 minutes. After two washes with staining buffer, the cells were analyzed on a Beckman Coulter FC500 flow cytometer and CXP 
software. At least 300,000 cells were counted from each sample. Appropriate isotypic controls were included in all experiments. The specific response of the cells to PMA/Ionomycin is calculated by substracting the percentage of positive events in the unstimulated sample from the percentage of positive events in the activated sample. Results were expressed as net percentage of cytokine positive cells.

\section{Statistical Analysis}

Results are presented as median, interquartile ranges (IQR: $25^{\text {th }}-75^{\text {th }}$ percentiles), and ranges $\left(5^{\text {th }}-95^{\text {th }}\right.$ percentiles). Statistical analysis was performed with SigmaPot v. 11.0 software (SyStat Software Inc, USA). A non-parametric Mann-Whitney Rank Sum Test or Student's $t$-test was used. Correlation analysis was performed using a Spearman's rank test. A $p$ value less than 0.05 was considered statistically significant. 


\section{RESULTS}

\section{Percentage and number of total iNKT cells in AD patients}

Circulating iNKT cells were identified as CD3+6B11+ cells among the lymphocytes of PBMCs obtained from peripheral blood of AD patients and HCs. The flow cytometry gating strategy is shown in Fig. 1a-c. Notably, the frequency of CD3+6B11+ iNKT cells was significantly reduced $(p=0.003)$ in AD patients (0.07\%; IQR: 0.040-0.155\%) compared with HCs (0.295\%; IQR: $0.125-0.430 \%)$ (Fig. 1d). In addition, the median circulating number of iNKT cells was also significantly diminished $(p<0.001)$ in AD patients $(0.394$ cells/ $\mu \mathrm{L}$; IQR: $0-2.029$ cells $/ \mu \mathrm{L})$ compared with the controls (4.921 cells/ $\mu \mathrm{L}$; IQR: 2.856-11.076 cells/ $\mu \mathrm{L})$ (Fig. 1e).

Because alteration in the $\mathrm{T}$ cell numbers may affect the iNKT cell count, we determined the percentage of the CD3+ T cell, CD4+, CD8+ T cell subsets and the CD4/CD8 ratio in PBMC of both AD patients and HCs, and in this sense the AD population did not differ significantly from the investigated controls (data not shown). No correlations were found between the frequency or number of iNKT cells and the age or sex of the patients, disease severity (measured by the SCORAD index), or the serum levels of total IgE and LDH.

\section{Subgroup analysis of iNKT cells in AD patients}

Among the gated CD3/6B11 double positive total iNKT cells, the four iNKT subsets were identified on the basis of their CD4 and CD8 expression (Fig. 1c). Analysis of the CD4/CD8 phenotype of iNKT cells revealed a significant decrease in the percentage of CD4subpopulations (DN and CD4-CD8+) ( $p=0.016$ for DN; $p=0.03$ for CD4-CD8+) in AD patients compared with HCs. When the absolute numbers were counted, the results showed an even more pronounced decrease in the CD4/CD8 iNKT subpopulations of AD patients compared with HCs 
( $p<0.001$ for all cases). The detailed results of the iNKT subset analysis are summarized in Table I.

Positive correlations were found between the frequency of total iNKT cells and the frequencies of their subsets in AD patients ( $p<0.01$ for all cases) except for DP iNKT cells (Fig. 1f), and these correlations were more pronounced $(p<0.001)$ when the absolute cell counts were analyzed (Fig. 1g). Presumably, the very low number of cells in the DP iNKT subset accounts for the absence of the aforementioned relationships and data for this subset are not presented in Fig. 1f, g. The correlation coefficients (r) for percentage of iNKT subsets were $r_{\mathrm{DN}}=0.741 ; \mathrm{r}_{\mathrm{CD} 4+\mathrm{CD} 8-}$ $=0.631 ; \mathrm{r}_{\mathrm{CD} 4-\mathrm{CD} 8+}=0.452 ;$ and $\mathrm{r}_{\mathrm{DP}}=\mathrm{n} . \mathrm{s}$, and for absolute counts were $\mathrm{r}_{\mathrm{DN}}=0.929 ; \mathrm{r}_{\mathrm{CD} 4+\mathrm{CD} 8}=0.922$; $\mathrm{r}_{\mathrm{CD} 4-\mathrm{CD} 8+}=0.856$; and $\mathrm{r}_{\mathrm{DP}}=0.392$. For both the frequencies and the absolute numbers, the strongest correlation was found between the values of the total iNKT group and the DN iNKT subgroup.

\section{Functional analysis of iNKT cells in AD patients}

To assess the effector functions of iNKT cells in AD patients, the intracellular IFN $\gamma$ and IL-4 cytokine content of total iNKT cells and subgroups was determined. After comparing cells from $10 \mathrm{AD}$ patients and $10 \mathrm{HCs}$, the intracellular IFN $\gamma$ expression was found to be decreased (Fig. 2a, b), whereas that of IL-4 was increased (Fig. 3a, b) in the total iNKT cells from AD patients compared with those from HCs; however, these alterations did not reach the limit of statistical significance. Next, the functional properties of the different subsets of iNKT cells were analyzed. When the intracellular cytokine levels of iNKT subgroups from AD patients and HCs were compared, the DN iNKT subgroup from AD patients exhibited significantly lower IFN $\gamma$ levels ( $p<0.05$; Fig. 2 c) and significantly increased intracellular IL-4 levels $(p<0.01$; Fig. 3c).

With respect to the other three iNKT subgroups, no significant differences were detected in the intracellular IFN $\gamma$ and IL-4 cytokine levels between AD patients and controls. 


\section{DISCUSSION}

Although considerable evidence suggests a role for iNKT cells in autoimmune and infectious disorders, there are scarce data on their distribution and function in atopic diseases. The involvement of iNKT cells in bronchial asthma has been extensively investigated by studies utilizing animal models of allergen-induced asthma, ozone exposure, viral infection or bacterial components, which conclude that iNKT cells function either in concert with $\mathrm{Th} 2$ cells or independently of adaptive immunity to cause airway hyperreactivity [31]. On the other hand, data on the role of iNKT cells in human asthma are conflicting, since some authors found iNKT cells in low numbers in the airways of subjects with asthma, while others reported opposite results $[32,33]$.

iNKT cells are able to produce large amounts of Th1 and Th2 type cytokines upon activation, which suggests that they may play a role in the pathogenesis of another atopic disease, such as AD. So far, there have been few and conflicting data published on iNKT cells in AD; the contrary findings can be explained by the different sensitivities and specificities of the distinct methods that were used for the detection of these cells. Currently, CD1d multimers or invariant TCR $\alpha$ chain specific 6B11 monoclonal antibodies are regarded as the most accurate markers for the identification of iNKT cells by flow cytometry [30, 34, 35]. In this study, by using an anti$\mathrm{CD} 3 / 6 \mathrm{~B} 11 \mathrm{mAb}$ combination to characterize iNKT cells, we were able to show that both the percentage and the number of iNKT cells were significantly decreased in the peripheral blood of patients with $\mathrm{AD}$ compared with HCs. In our study the number of iNKT cells in the HCs was higher than usually observed by other investigators. The mean age was about 18 years for HCs and we believe that the higher number of iNKT cells in this population can partly be explained by the younger age $[36,37]$. On the other hand a high inter-individual variation in the frequency 
of iNKT cells can also been considered [38, 39]. There was no alteration found in the frequency of the total $\mathrm{T}$ cells and the CD4/CD8 subsets in AD patients, presuming that the reduction in the prevalence of iNKT cells was not resulted from differences in T cell populations.

In agreement with our results, four previous publications demonstrated diminished numbers of iNKT cells in AD patients; conversely, two groups found increased numbers of these cells $[25,40-43,26]$. These contradictory results suggest that further investigations are needed, as it is possible that not only differences in the applied methods but also differences in the patient selection (extrinsic-intrinsic AD, mild-moderate-severe $\mathrm{AD}$ ) may alter the iNKT cell number. It is important to emphasize that among the above-mentioned studies only one employed a method similar to ours.

Using phenotypic analysis of the CD4/CD8 subsets of iNKT cells, we investigated which subpopulation was mainly responsible for the decreased iNKT number in AD patients. In HCs, we found that the CD4+CD8- and DN subpopulations of iNKT cells were the most frequent subpopulations and both of them represented a similar percentage of iNKT cells, the CD8+CD4iNKT cells had an intermediate frequency, and the DP iNKT cells had the lowest frequency. Montoya et al. demonstrated similar prevalence of iNKT subsets in healthy individuals, while various frequencies of these subsets have also been reported [30, 44, 45]. In the peripheral blood of patients with $\mathrm{AD}$, the most pronounced alteration was observed in the DN iNKT subset. Although the numbers of all iNKT subsets were found to be decreased, only CD4- (DN and CD4-CD8+) iNKT subsets showed significantly diminished percentages in AD patients. The strongest positive correlation was found between the DN iNKT subset and total iNKT cells. These findings are consistent with the results of previous studies. Takahashi et al. detected a decreased tendency of CD4-CD8+ and DN iNKT subsets, while Oishi et al. found a greatly 
diminished DN iNKT cell number in patients with asthma and with $\mathrm{AD}[25,41]$. In contrast to these results, some authors reported significantly reduced CD4+ iNKT subset in the peripheral blood of patients with AD [46]. The cause for the varied results of the different reports on iNKT subsets are unknown, but may arise from a distinct patient population selection or a difference in gating on CD4+ and CD8+ iNKT subsets, namely, whether dimly positive cells were involved in these studies.

Differentiating between iNKT subsets is crucially important because distinct subsets may have different functions [34, 47, 48]; furthermore, a cross-regulation between the various iNKT subsets markedly influences the immune response to self and foreign antigens [49]. In healthy individuals, the circulating CD4+ iNKT subset can produce both Th1 and Th2 cytokines (IFN $\gamma$, IL-4 and IL-13), whereas the DN iNKT subset secretes predominantly Th1 cytokines (IFN $\gamma$ and $\mathrm{TNF} \alpha)[10,34]$. Elimination of pathogens and tumour rejection are generally correlated with Th1 responses, whereas tolerogenic mechanisms, such as suppression of graft rejection and inhibitory effects, are usually associated with Th2 responses by iNKT cells [50].

Because data on the number of iNKT cells or even iNKT subgroups are limited if functional properties are not analyzed, intracellular IFN $\gamma$ and IL-4 cytokine production were also measured. We have found that the overall IFN $\gamma$ production by iNKT cells was decreased, whereas the IL-4 production was increased, in AD patients; however, these alterations were not significant. On the other hand, these functional alterations were significant when the DN subgroup was investigated. The DN iNKT cells from AD patients produced significantly less IFN $\gamma$ and significantly more IL-4 compared with HCs. According to our best knowledge, this is the first demonstration of the altered intracellular cytokine pattern in the DN iNKT subgroup of AD patients. 
The significantly decreased number and altered function of iNKT cells demonstrated in our results are in good agreement with previous studies, which found that increased plasma IL18 level in $\mathrm{AD}$ patients correlated with the decreased number and dysfunction of iNKT cell in these patients [46]. Lind et al. found that elevated plasma levels of IL-18 exerted an inhibitory effect on iNKT cells and that IL-18-mediated dysregulation of iNKT cells may play a role in the pathogenesis of AD.

It is a yet unsolved question whether changes in the number and cytokine expression of total iNKT cells or iNKT subgroups may act as primary pathogenic factors in the development of $\mathrm{AD}$, or whether the disease is a consequence of elevated Th2-type cytokine levels in the peripheral blood of these patients. The decreased number and altered cytokine production of iNKT cells may lead to an impaired immuno-regulatory capacity of these cells, which could contribute to the development of the characteristic cytokine milieu and chronic inflammation observed in AD patients. Aberrations of the adaptive immune system in the peripheral blood and skin of $\mathrm{AD}$ patients are well studied, but less is known about the alterations of the innate immune system $[3,51]$. Presently, a great deal of evidence suggests that there are various defects in the different components of the innate immune system, such as a reduction in antimicrobial peptide production, lower expression of toll-like receptors, disruption of the epithelial barrier and diminished recruitment of innate immune cells to the skin [7]. Hence, the present study also highlights the possible role of the innate immune system in a chronic inflammatory skin disease, which was previously considered to be influenced mainly by the components of the adaptive immune system.

In conclusion, the significantly altered number and cytokine production of iNKT cells of $\mathrm{AD}$ patients suggest that these cells may play an important role in the pathogenesis of AD. 


\section{Acknowledgements}

We acknowledge the excellent technical assistance of Mrs. Marianna Száraz. This work was supported by Hungarian Research Grants (OTKA K81381, ETT-059-05, TÁMOP-4.2.208/1/2008-0019). 


\section{REFERENCES}

1. Boguniewitz M, Leung DYM. Atopic dermatitis. J. Allergy Clin. Immunol. 117: S47580,2008

2. Bieber T. Atopic dermatitis. Ann. Dermatol. 22: 125-37, 2010

3. Grewe M, Brujnzeel-Koonen C, Schöpf E, Thepen T, Langeveld-Wildschut AG, Ruzicka T, Krutmann J: A role for Th1 and Th2 cells in the immunopathogenesis of atopic dermatitis. Immunol. Today 19: 359-61, 1998

4. Szegedi A, Baráth S, Nagy G, Szodoray P, Gál M, Sipka S, Bagdi E, Banham AH, Krenács L: Regulatory T cells in atopic dermatitis: epidermal dendritic cell clusters may contribute to their local expansion. Br. J. Dermatol. 160: 984-93, 2009

5. Nograles KE, Zaba LC, Shemer A, Fuentes-Duculan J, Cardinale I, Kikuchi T, Ramon M, Bergman R, Krueger JG, Guttmann-Yassky E: IL-22-producing „T22” T cells account for upregulated IL-22 in atopic dermatitis despite reduced IL-17-producing $\mathrm{T}_{\mathrm{H}} 17 \mathrm{~T}$ cells. J. Allergy Clin. Immunol. 123: 1244-52, 2009

6. Koga C, Kabashima K, Shiraishi N, Kobayashi M, Tokura Y. Possible Pathogenic role of Th17 cells for atopic dermatitis. J. Invest. Dermatol. 128: 2625-30, 2008

7. De Benedetto A, Agnihothri R, McGirt LY, Bankova LG, Beck LA: Atopic dermatitis: A disease caused by innate immune defects? J. Invest. Dermatol. 129: 14-30, 2009 
8. Cork MJ, Danby SG, Vasilopoulos Y, Hadgraft J, Lane ME, Moustafa M, Guy RH, Macgowan AL, Tazi-Ahnini R, Ward SJ. Epidermal dysfunction in atopic dermatitis. J. Invest. Dermatol. 129: 1892-908, 2009

9. Godfrey DI., Kronenberg M: Going both ways: immune regulation via CD1d-dependent NKT cells. J. Clin. Invest. 114: 1379-87, 2004

10. Kronenberg M and Gapin L: The unconventional lifestyle of NKT cells. Nat. Rev. Immunol. 2: 557-68, 2002

11. Bendelac A, Rivera MN, Park SH, Roark JH: Mouse CD1-specific NK1 T cells: development, specificity, and function. Ann. Rev. Immunol. 15: 535-62, 1997

12. Porcelli S, Yockey CE, Brenner AB, Balk SP,: Analysis of T cell antigen receptor (TCR) expression by human peripheral blood CD4-8-alpha/beta $\mathrm{T}$ cells demonstrates preferential use of several V beta genes and an invariant TCR alpha chain. J. Exp. Med. 178: 1-16, 1993

13. Godfrey D, Hammond K, Poulton L, Smyth M, Baxter A: NKT cells: Facts, functions and fallacies. Immunol. Today 21: 573-583, 2000

14. Exley M, Garcia J, Balk SP, Porcelli S: Requirements for CD1d recognition by human invariant Valpha24+ CD4-CD8- T cells. .J. Exp. Med. 186: 109-20, 1997 
15. Balato A, Unutmaz D and Gaspari AA. Natural killer T cells: An unconventional T-cell subset with diverse effector and regulatory functions. J. Invest. Dermatol. 129: 1628-42, 2009

16. Van Kaer L, Parekh VV, Wu L: Invariant natural killer T cells: bridging innate and adaptive immunity. Cell Tissue Res. 343: 43-55, 2011

17. Taniguchi M. Harada M, Kojo S, Nakayama T, Wakao H. The regulatory role of Valpha14 NKT cells in innate and acquired immune response: Ann. Rev. Immunol. 21: 483-513, 2003

18. Wu L, Van Kaer: Natural killer T cells and autoimmune disease. Curr. Mol. Med. 9: 414, 2009

19. Van der Vliet H J, von Blomberg M E, Nishi N, Reijm M, Voskuyl A E, van Bodegraven A, Polman C H, Rustemeyer T, Lips P, van den Eertwegh A J, Giaccone G, Scheper RJ, Pinedo HM: Circulating V $\alpha 24+\mathrm{V} \beta 11+$ NKT cell numbers are decreased in a wide variety of diseases that are characterized by autoreactive tissue dammage. Clin. Immunol. 100: $144-8,2001$

20. Sumida T, Sakamoto H, Murata A, Makino Y, Takahashi H, Yoshida S, Nishioka K, Iwamoto Y, Taniguchi M: Selective reduction in $\mathrm{T}$ cells bearing invariant $\mathrm{V}$ alpha $24 \mathrm{~J}$ alpha Q antigen receptor in patients with systemic sclerosis. J. Exp. Med. 182: 1163-8, 1995 
21. Godó M, Sessler T, Hamar P: Role of invariant natural killet T (iNKT) cells in systemic lupus erythematosus. Curr. Med. Chem. 15: 1778-87, 2008

22. Novak J, Griseri T, Beaudoin L, Lehuen A: Regulation of type 1 diabetes by NKT cells. Int. Rev. Immunol. 26: 49-72, 2007

23. Simon D, Kozlowski E, Simon H: Natural killer T cells expressing IFN-gamma and IL-4 in lesional skin of atopic eczema. Allergy 64: 1681-4, 2009

24. Gober MD, Fishelevich R, Zhao Y, Unutmaz D, Gaspari AA: Human natural killer T cells infiltrate into the skin at elicitation sites of allergic contact dermatitis. J. Invest. Dermatol. 128: 1460-9, 2008

25. Takahashi T, Nakamura K, Chiba S Kanda Y, Tamaki K, Hirai H: Va24+ natural killer T cells are markedly decreased in atopic dermatitis patients. Hum. Immunol 64: 586-92, 2003

26. Magnan A, Mély L, Prato S, Vervloet D: Relationships between natural T cells, atopy, IgE levels, and IL-4 production. Allergy 55: 286-90, 2000

27. Hanifin JM, Rajka G. Diagnostic features of atopic dermatitis. Acta Derm. Venereol. Suppl. 92: 44-7, 1980

28. Severity scoring of atopic dermatitis: the SCORAD index. Consensus Report of the European task force on Atopic Dermatitis. Dermatology. 186: 29-31, 1993 
29. Wolkerstorfer A, de Waard van der Spek FB, Glazenburg EJ, Mulder PG, Oranje AP. Scoring the severity of atopic dermatitis: Three item severity Score as a Rough System for Daily Practice and as a pre-screening tool for studies. Acta Derm. Venereol. 79: 356$359 ; 1999$

30. Montoya CJ, Pollard D, Martinson K, Kumari K, Wasserfall C, Mulder CB, Rugeles MT, Atkinson MA, Landay AL, Wilson SB: Characterization of human invariant natural killer $\mathrm{T}$ subsets in health and disease using a novel invariant natural killer $\mathrm{T}$ cell-clonotypic monoclonal antibody, 6B11. Immunology 122: 1-14, 2007

31. Umetsu DT, DeKruyff RH. Natural killer T cells are important in the pathogenesis of asthma: The many pathways to asthma. J. Allergy Clin. Immunol. 125: 975-9, 2010

32. Akbari O, Faul JL, Hoyte EG, Berry GJ, Wahlstrom J, Kronenberg M, DeKruyff MH, Umetsu DT. CD4+ invariant T-cell-receptor+ natural killer T cells in bronchial asthma. N. Engl. J. Med. 354: 1117-29, 2006

33. Vijayanand P, Seumois G, Pickard C, Gadola SD, Friedmann PS, Djukanovicz R. Invariant natural killer $\mathrm{T}$ cells in asthma and chronic obstructive pulmonary disease. $\mathrm{N}$. Eng. J. Med. 356: 1410-22, 2007

34. Gumperz JE, Miyake S, Yamamura T, Brenner MB: Functionally distinct subsets of CD1d-restricted Natural Killer T Cells revealed by CD1d tetramer staining. J. Exp. Med. 195: 625-36, 2002 
35. Metelitsa LS: Flow cytometry for natural killer T cells: multiparameter methods for multifunctional cells. Clin. Immunol.110: 267-76, 2004

36. Jing Y, Gravenstein S, Chaganty NR, Chen N, Lyerly KH, Joyce S, Deng Y. Aging is associated with a rapid decline in frequency, alterations in subset composition, and enhanced Th2 response in CD1d-restricted NKT cells from human peripheral blood. Exp. Gerontology 42: 719-732; 2007.

37. Molling JW, Kölgen W, van der Vliet HJ, Boomsman MF, Ktruizenga H, Smorenburg CH, Molenkamp BG, Langendijk JA, Leemans CR, von Blomberg BME, Scheper RJ, van den Eerthwegh AJM. Peripheral blood IFN- $\gamma$-secreting V $\alpha 24+V \beta+$ NKT cell numbers are decreased in cancer patients independent of tumor type or tumor load. Int. J. Cancer 116: 87-93, 2005

38. Davodeau F, Peyrat MA, Necker A, Dominici R, Blanchard F, Leget C, Gaschet J, Costa P, Jacques Y, Godard A, Vie H, Poggi A, Romagné F, Bonneville M. Close phenotypic and functional similarities between human and murine alphabeta $\mathrm{T}$ cells expressing invariant TCR alpa-chains. J. Immunol. 158: 5603-11, 1997

39. Prussin C, Foster B. TCR V alpha 24 and V beta 11 coexpression defines a human NK1 T cell analog containing a unique Th0 subpopulation. J. Immunol. 159: 5862-70, 1997 
40. Ilhan F, Kandi B, Akbulut H, Turgut D, Cicek D: Atopic dermatitis and Valpha24+ natural killer T cells. Skinmed 6: 218-20, 2007

41. Oishi Y, Sakamoto A, Nakajama H, Nakao A, Nakagawa N Tanabe E, Saito Y, Iwamoto I. CD4-CD8- T cells bearing invariant V $\alpha 24 \mathrm{~J} \alpha \mathrm{Q}$ TCR $\alpha$-chain are decreased in patients with atopic diseases. Clin. Exp. Immunol. 119: 404-11, 2000

42. Prell C, Konstantopoulos N, Heinzelmann B, Frankenberger B, Reinhard D, Schendel D, Krauss-Etschmann S. Frequency of $\mathrm{V} \alpha 24^{+} \mathrm{CD} 161^{+}$natural killer $\mathrm{T}$ cells and invariant TCRAV24-AJ18 transcripts in atopic and non-atopic individuals. Immunobiol. 280: 36780,2003

43. Wu WH, Park CO, Oh SH, Kim HJ, Kwon YS, Bae BG, Noh JY, Lee KH. Thymic stromal lymphopoietin-acivated natural killer $\mathrm{T}$ cells trigger an innate allergic immune response in atopic dermatitis. J Allergy Clin Immunol 126: 290-9, 2010

44. Croudace JE, Curbishley SM, Mura M, Wilcox CR, Illarionov PA, Besra GS, Adams DH, Lammas DA. Identification of distinct human invariant natural killer T-cell response phenotypes to alpha-galactosylceramide. BMC Immunol. 9: 71, 2008

45. Im JS, Kang TJ, Lee SB, Kim CH, Lee SH, Venkataswamy MM, Serfass ER, Chenn B, Illarionov PA, Besra GS, Jacobs WR Jr, Chae GT, Porcelli SA. Alteration of the relative levels of iNKT cell subsets is associated with chronic mycobacterial infections. Clin. Immunol. 127: 214-24, 2008 
46. Lind SM, Kuylenstierna C, Moll M, Jordö ED, Winquist O, Lundenberg L, Karlsson MA, Linder MT, Johansson C, Scheynius A, Sandberg JK, Karlsson MCI: IL-18 skews the invariant NKT-cell population via autoreactive activation in atopic eczema. Eur. J. Immunol. 39: 2293-301, 2009

47. Seino K, Taniguchi M: Functionally distinct NKT cell subsets and subtypes. J. Exp. Med. 202: 1623-6, 2005

48. Lee PT, Benlagha K, Teyton L Bendelac A: Distinct functional lineages of Va24 natural killer T cells. J. Exp. Med. 195: 637-41, 2002

49. Arrenberg P, Halder R, Kumar V: Cross-regulation between distinct natural killer T cell subsets influences immune response to self and foreign antigens. J. Cell Physiol. 218: 246-50, 2009

50. Wang Z, Kusam S, Munugalavadla V, Kapur R, Brutkievicz RR, Dent AL: Regulation of Th2 cytokine expression in NKT cells: Unconventional use of Stat6, Gata-3, and NFAT2. J. Immunol. 176: 880-8, 2006

51. Aleksza M, Lukács A, Antal-Szalmás P, Hunyadi J, Szegedi A: Increased frequency of intracellular interleukin (IL)-13 and IL-10, but not IL-4, expressing CD4+ and CD8+ peripheral T cells of patients with atopic dermatitis. Br. J. Dermatol. 147: 1135-41, 2002 
Table I. iNKT cells and iNKT subsets in AD patients

\begin{tabular}{|c|c|c|c|c|c|c|c|c|c|c|}
\hline \multirow{3}{*}{$\begin{array}{l}\text { iNKT } \\
\text { SUBSET }\end{array}$} & \multicolumn{5}{|c|}{$\begin{array}{c}\text { FREQUENCY } \\
(\%)\end{array}$} & \multicolumn{5}{|c|}{$\begin{array}{c}\text { ABSOLUTE NUMBER } \\
(\text { cells/uL) }\end{array}$} \\
\hline & \multicolumn{2}{|c|}{ AD } & \multicolumn{2}{|c|}{ HCs } & & \multicolumn{2}{|c|}{ AD } & \multicolumn{2}{|r|}{ HCs } & \multirow[b]{2}{*}{$p$-value } \\
\hline & Median & IQR & Median & IQR & $p$-value & Median & IQR & Median & IQR & \\
\hline Total & 0.070 & $0.040-0.155$ & 0.295 & $0.125-0.430$ & 0.003 & 0.394 & $0-2.029$ & 4.921 & $2.156-11.076$ & $<0.001$ \\
\hline CD4+CD8- & 0.030 & $0.020-0.085$ & 0.090 & $0.020-0.150$ & 0.090 & 0.181 & $0-0.722$ & 2.120 & $0.875-3.508$ & $<0.001$ \\
\hline DN & 0.030 & $0.010-0.070$ & 0.090 & $0.060-0.190$ & 0.016 & 0.163 & $0-0.943$ & 1.533 & $0.892-5.111$ & $<0.010$ \\
\hline CD4-CD8+ & 0.010 & $0-0.035$ & 0.070 & $0.020-0.100$ & 0.030 & 0 & $0-0.495$ & 1.330 & $0.632-1.882$ & $<0.001$ \\
\hline DP & 0 & $0-0.015$ & 0.010 & $0.008-0.020$ & 0.052 & 0 & $0-0$ & 0.325 & $0-0.444$ & $<0.001$ \\
\hline
\end{tabular}

Median and interquartile ranges (IQR) of frequency and absolute number of iNKT cells and their subsets are presented for 41 AD patients and $16 \mathrm{HCs}$. $A D$ atopic dermatitis, $H C s$ healthy controls, $D N$ double negative, $D P$ double positive. ${ }^{\text {a }}$ Difference between study groups (Mann Whitney U-test or Student's t-test). 


\section{FIGURE LEGENDS}

\section{Figure 1. Flow cytometric analysis of iNKT cells and subsets from AD patients and HCs.}

PBMCs were stained with anti-CD3-FITC and 6B11-PE mAbs. a Lymphocytes were gated on a forward scatter (FS) - side scatter (SS) dot plot. b In the lymphocyte gate, iNKT cells were identified as CD3+6B11+ double positive cells. c Phenotypic analysis of iNKT cells was performed by CD4/CD8 staining with anti-CD4-ECD and anti-CD8-PC7 mAbs. d Percentage and $\mathbf{e}$ absolute number of iNKT cells detected in the lymphocyte gate are shown. Significantly reduced percentage $(\mathrm{p}=0.003)$ and absolute number $(p<0.001)$ of iNKT cells were found in AD patients $(n=41)$ compared with HCs $(n=16)$. Results are presented as medians, IQRs, and ranges $\left(5^{\text {th }}\right.$ and $95^{\text {th }}$ percentiles). Statistical significance was calculated using a Mann-Whitney U-test. $\mathrm{f}$ and $g$ These figures illustrate that the alteration of the CD4/CD8 iNKT subsets (y axis) show correlation with the decrease in the total iNKT cell ( $\mathrm{x}$ axis) percentage (f) and the absolute numbers $(\mathrm{g})$. The strongest correlation was detected between the total iNKT cells and the DN subset.

The upper long dash-line with empty circle symbols illustrates DN iNKT vs. total iNKT cells; the middle solid line with filled circle symbols represents CD4+CD8- vs. total iNKT cells; the lowest short dashed-double dotted line with diamond semi-filled bottom symbols illustrates CD4-CD8+iNKT vs. total iNKT cells (due to their low number, DP iNKT cells are not presented). Correlation coefficients ( $r$ ) and $\mathrm{p}$ values for significance can be found at the end of the regression lines on the right side of the plots. The Spearman correlation was significant $(p<0.05)$, except for the percentage of DP iNKT. *: $p<0.05 ; * *: p<0.001 ; * * *: p<0.0001$. Correlation coefficients (r) for percentages/absolute numbers of iNKT subsets: $\mathrm{r}_{\mathrm{DN}}=0.741 / 0,929$; $\mathrm{r}_{\mathrm{CD} 4+\mathrm{CD} 8}=0.631 / 0,922 ; \mathrm{r}_{\mathrm{CD} 4-\mathrm{CD} 8}=0.452 / 0,856 ; \mathrm{r}_{\mathrm{DP}}=$ n.s. $/ 0.392$. 


\section{Figure 2. Intracellular IFN $\gamma$ expression of iNKT cells.}

After stimulation of PBMCs obtained from AD patients and HCs with PMA/ionomycin for four hours, the cells were stained with CD4-ECD, 6B11-PE, CD8-PC7 and CD3-APC surface markers, followed by intracellular IFN $\gamma$-FITC staining. Cells were analyzed on a Coulter FC500 flow cytometer. a Representative scatter plots displaying lymphocyte (Ly) gates and iNKT gates of unstimulated and PMA/Ionomycin (Io) activated samples from an AD patient and HCs are presented. b Frequency of intracellular IFN $\gamma$ positive cells was diminished in total CD3+6B11+ iNKT cells from AD patients compared with HCs. c Frequency of intracellular IFN $\gamma$ in CD4+CD8-, DN (CD4-CD8-) and CD4-CD8+ iNKT subsets in AD patients and HCs. Compared to $\mathrm{HCs}$, patients with $\mathrm{AD}$ displayed significant reduction in the percentage of $\mathrm{DN}$ iNKT cells $(p<0.05$; Mann-Whitney U-test). The net percentage of IFN $\gamma$ positive cells was calculated by substracting the percentage of positive events in the unstimulated sample from the percentage of positive events in the activated sample. Boxes show net percentages of IFN $\gamma$ positive cells, median, IQR, and ranges ( $5^{\text {th }}$ and $95^{\text {th }}$ percentiles $), *: p<0.05$.

\section{Figure 3. Intracellular IL-4 expression of iNKT cells}

After stimulation of PBMCs obtained from AD patients and HCs with PMA/ionomycin for four hours, the cells were stained with CD4-ECD, 6B11-PE, CD8-PC7 and CD3-FITC surface markers, followed by intracellular IL-4-APC staining. The cells were analyzed on a Coulter FC500 flow cytometer. a Representative scatter plots displaying lymphocyte (Ly) gates and iNKT gates of unstimulated and PMA/Ionomycin (Io) activated samples from one AD patient and one control are presented. b Frequency of intracellular IL-4 positive cells was elevated in total $\mathrm{CD} 3+6 \mathrm{~B} 11+\mathrm{iNKT}$ cells in $\mathrm{AD}$ patients compared with HCs. $\mathbf{c}$ Frequency of intracellular IL-4 in CD4+CD8-, DN (CD4-CD8-) and CD4-CD8+ iNKT subsets in AD patients and HCs. 
Compared with HCs, patients with AD displayed significant enhancement in the percentage of DN iNKT cells expressing IL-4 ( $p<0.01$; Mann-Whitney U-test). The net percentage of IL-4 positive cells was calculated by substracting the percentage of positive events in the unstimulated sample from the percentage of positive events in the activated sample. Boxes show net percentages of IL-4 positive cells, median, IQR, and ranges ( $5^{\text {th }}$ and $95^{\text {th }}$ percentiles), $* *: p<0.01$. 
Fig. 1.
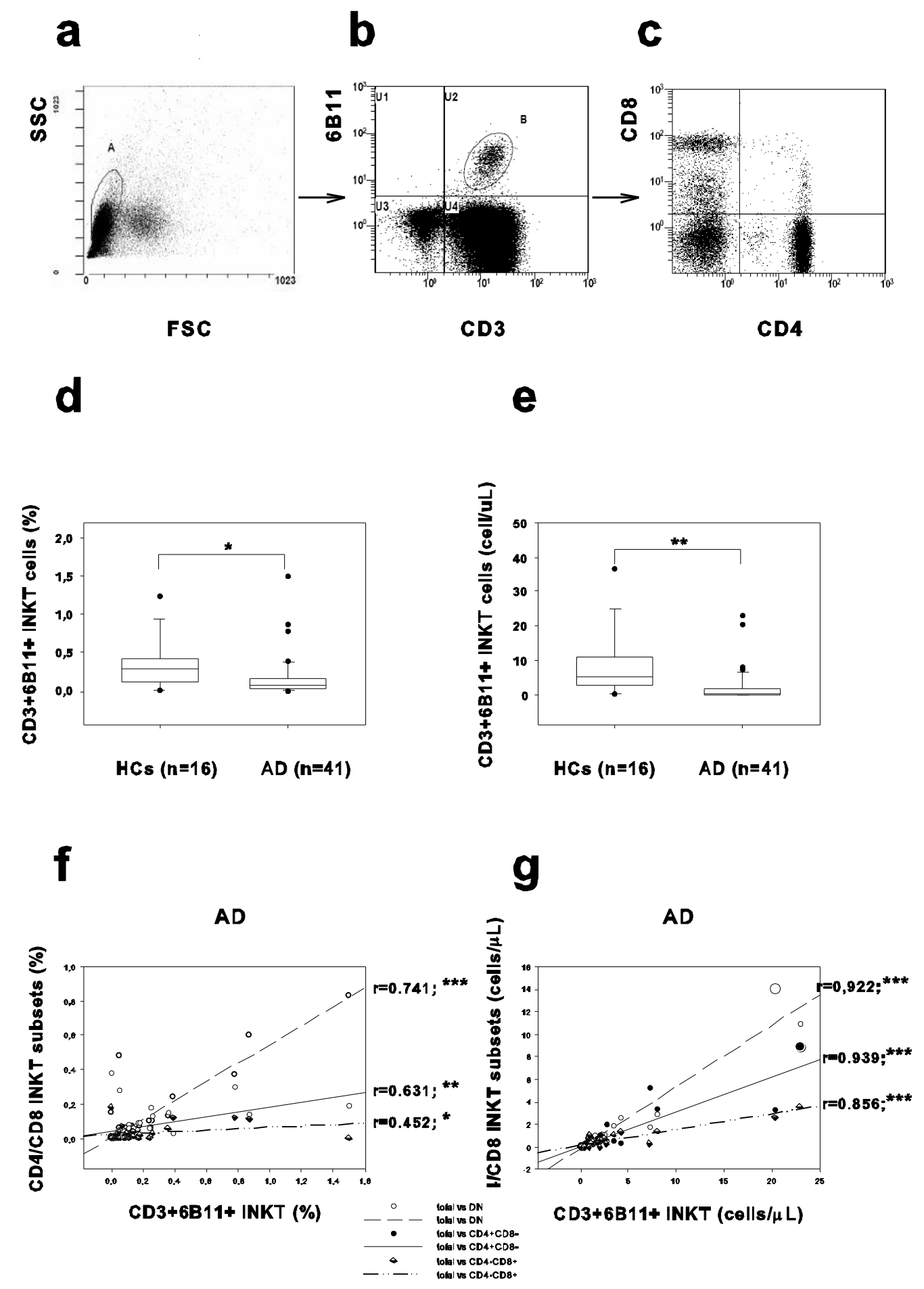
Fig. 2.

a

\section{Unstimulated}

Ly gate iNKT gate

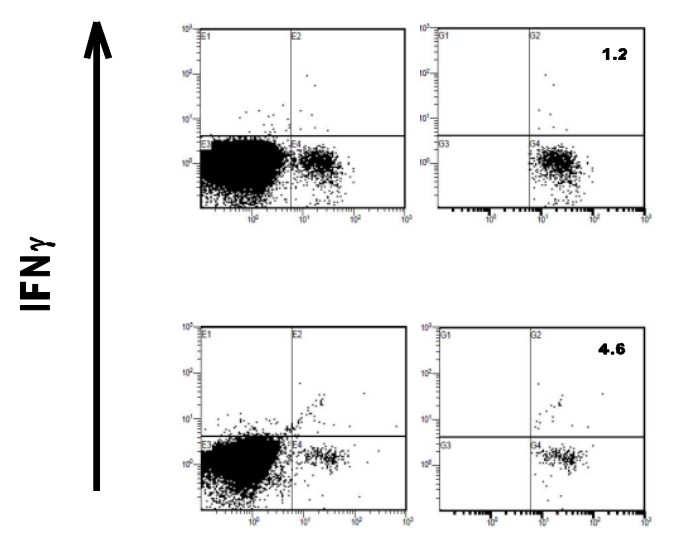

PMA/lo Activated

Ly gate iNKT gate
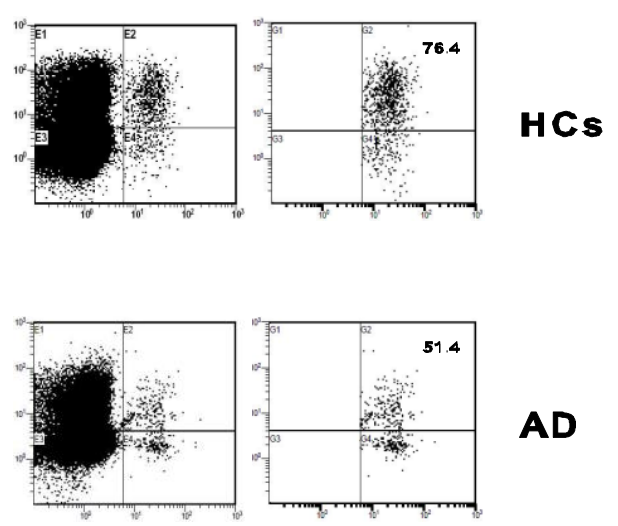

AD

6B11

b

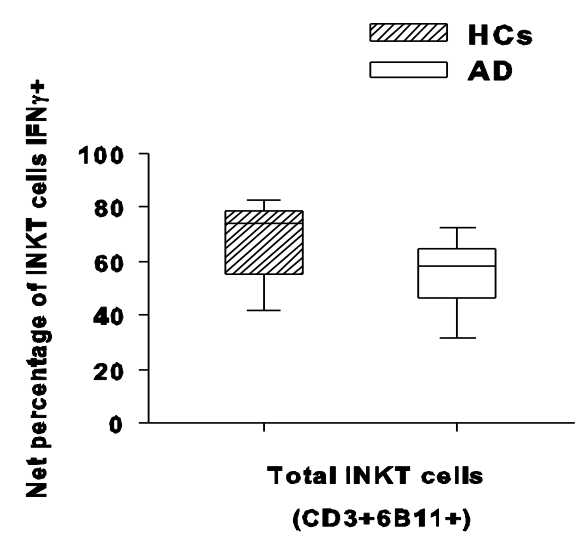

c

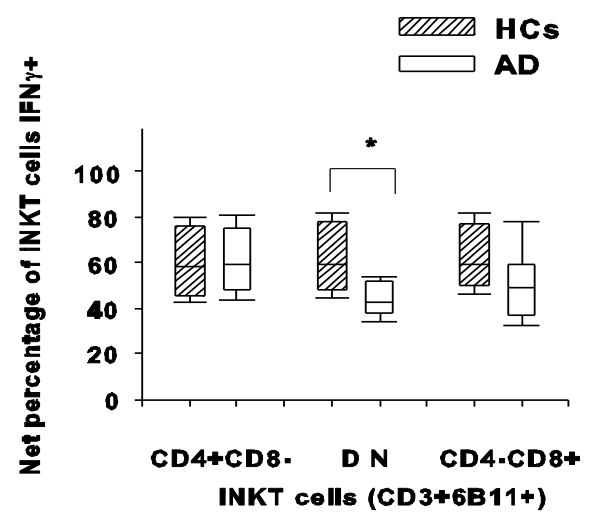


Fig. 3.

a

Unstimulated

Ly gate iNKT gate

$\mid$
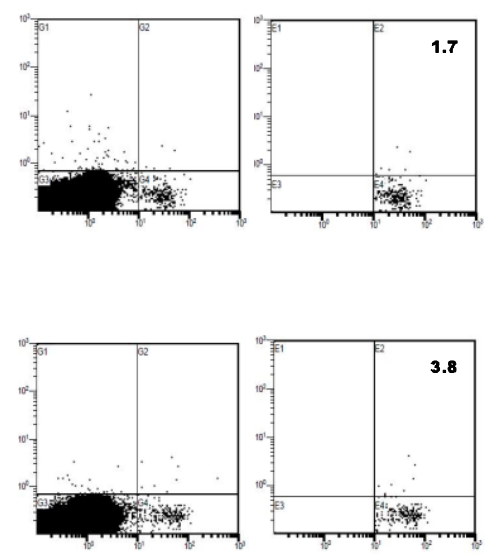

PMA/lo Activated

Ly gate iNKT gate

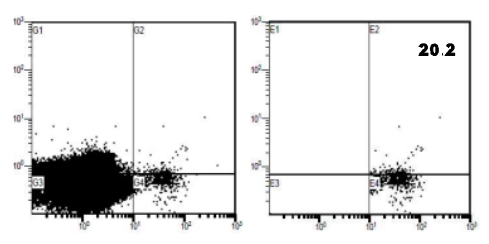

HCs

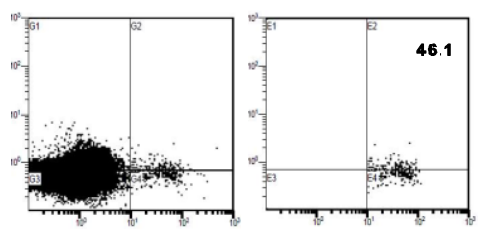

AD

6B11

b

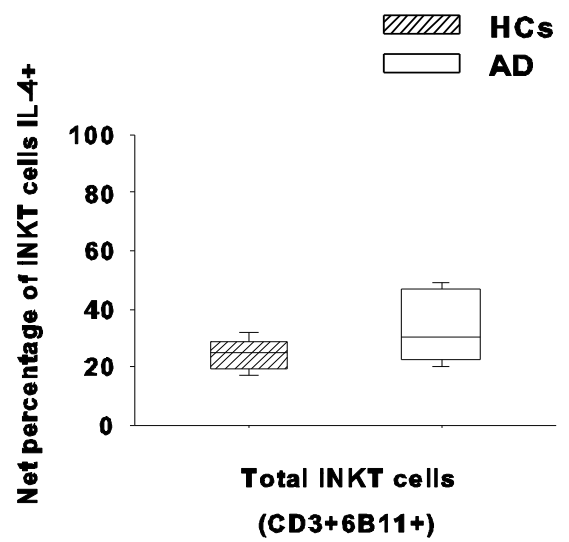

c

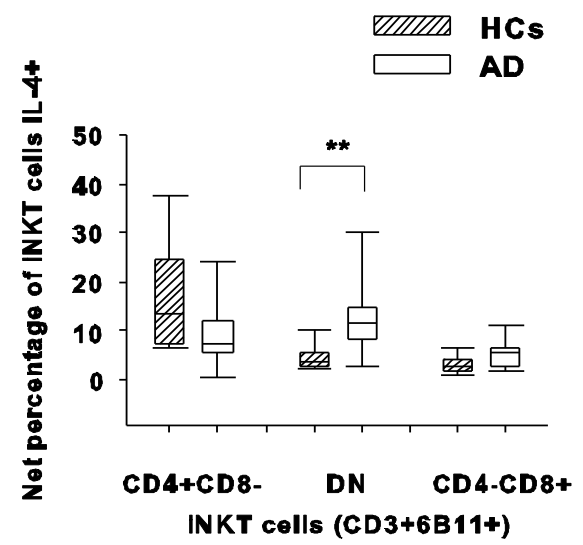

